\title{
Concepções freudianas sobre a irrupção da puberdade e a etiologia das neuroses ${ }^{1}$
}

\author{
Alessandra Aguiar Vieira*, Ângela Maria Resende Vorcaro \\ Universidade Federal de Minas Gerais - UFMG, Belo Horizonte, MG, Brasil
}

Resumo: Este trabalho tem como objetivo apreender a nuance do conceito de puberdade ao longo da obra freudiana. Buscamos compreender como Freud, tendo por base a interface entre "determinismo do período da infância" e "contingência adolescente", articula a puberdade com o momento de irrupção da neurose. Problematizaremos a relevância do "período de latência" e do pressuposto de uma sexualidade "em dois tempos" na compreensão da puberdade e de suas possibilidades no âmbito da constituição do sujeito. Utilizaremos como recurso metodológico a retomada dos principais casos clínicos de Freud, dentre eles, Dora, Homem dos Lobos e a Jovem homossexual, buscando apreender a relevância do momento da irrupção da puberdade, suas possibilidades, seus percalços na causação/manifestação da neurose. Percebemos que Freud, mesmo não tomando a questão como foco de sua pesquisa, passa por ela ao longo de sua obra, permitindo-nos inferir e discutir suas concepções acerca do tema.

Palavras-chaves: etiologia da neurose, irrupção da puberdade, infância, casos clínicos.

\section{Introdução}

A adolescência tornou-se, nos últimos anos, um tema de grande interesse para diversos pesquisadores, dentre os quais aqueles que se dedicam à Psicanálise. $\mathrm{O}$ crescente aumento de sintomas na contemporaneidade, como a violência entre jovens, anorexia, bulimia e uso de drogas, dentre tantos outros, colocam em evidência o tema da adolescência, demarcando a necessidade de se pensar em uma especificidade desse momento da vida, marcado por tantos acontecimentos no âmbito do psiquismo. Nesse sentido, inúmeros são os psicanalistas, mesmo que de Escolas diferentes, que abordam o tema, trazendo contribuições importantes para se pensar a travessia da adolescência (A. Freud, 1946; Winnicott, 1974; Aberastury, 1983; Braconnier, 1985; Ladame, 1985, Blos, 1986; Rassial, 1999; Alberti, 1999; Calligaris, 2000; Stevens, 2004, dentre tantos outros).

Porém, mesmo tendo como base de suas teorizações a obra de Freud, tais correntes, na grande maioria das vezes, tratam da perspectiva freudiana sobre a adolescência an passant, muitas vezes restringindo o enfoque a sua obra de referência, "Os três ensaios sobre a teoria da sexualidade" (Freud, 1905/1996). Nessa perspectiva, tais autores, no mais das vezes, tomam a obra de Freud apenas como ponto de partida para suas análises, com vistas a apropriarem-se também de outras referências tidas como principais, buscando, assim, "ir além" das palavras do criador da Psicanálise, mesmo nos casos em que não tenham o intuito de perdê-lo de vista. Em contrapartida, o que se percebe

1 Este artigo é parte de uma pesquisa de Mestrado em andamento junto ao Programa de Pós-graduação em Psicologia da Universidade Federal de Minas Gerais sob a orientação de Ângela Maria Resende Vorcaro.

* Autor correspondente: ale.aguiarvieira@yahoo.com.br nas vastas referências acerca do tema são formas diversas de se pensar e abordar a obra freudiana, distanciamento tal que pode ser compreendido pelo próprio estilo de Freud na escrita de seu texto principal acerca do tema, significativamente um dos trabalhos que mais sofreu modificações e acréscimos em toda sua teorização. Assim,

ainda que cada construção parta de Freud, este não parece ser o mesmo para cada um de seus sucessores e a disputa que então se estabelece gira em torno de qual seria o caminho que melhor representa $o$ espírito do velho mestre. (Matheus, 2007, p. 43)

Desta feita, diferentemente de tais autores, objetivamos nesse artigo propor um retorno à obra de Freud, tomando-a como fonte de análise, a fim de apreender e problematizar vestígios de suas conceituações nos episódios em que aborda a irrupção da puberdade, deixando em suspenso suas encruzilhadas, seus nós, que levaram, tantas vezes, a mudanças teóricas. Por outro lado, cabe também ressaltar o quanto a leitura freudiana, por ela mesma, torna-se um exercício difícil, principalmente tendo como referência leitores distantes de sua época de produção, estando sujeitos, pois, a outras determinações sócio-culturais, incidentes em suas experiências, que levam, muitas vezes, à difração do sentido dos termos recorrentes nesse período.

Ademais, não podemos deixar de considerar também a impossibilidade de reencontrar, na escrita freudiana, um suposto Freud-puro. Afinal, se o perseguíssemos, estaríamos desconsiderando suas próprias descobertas sobre a sistemática tradução das representações e seus vastos recobrimentos. Contudo, é considerando tais impasses como exercício metodológico que pretendemos trilhar um caminho, valorizando os próprios ensinamentos de Freud 
sobre a leitura e a escuta: o exercício do estranhamento, da interrogação, enfatizando, pois, a voz do texto, a partir de suas entonações, suas pausas, seus retornos, seu percurso. Trata-se, portanto, de tomar o texto freudiano como objeto de análise.

Conforme é notadamente sabido, ao longo de sua vasta obra, Freud não apresentou uma teorização sistemática acerca da adolescência, porém trouxe contribuições importantes sobre as consequências psíquicas oriundas da puberdade que, por sinal, foram se modificando de forma significativa no decorrer de suas formulações. Nesse sentido, raras são as referências ao termo "adolescência" em sua obra, o que pode demonstrar o próprio desuso do termo na época (Matheus, 2007). Desse modo, se atualmente há tantos autores que se preocupam em delimitar e circunscrever os conceitos de "adolescência" e "puberdade", é certo que o fundador da Psicanálise pouco se preocupou em diferenciá-los, restringindo-se a teorizar sobre a puberdade e suas influências (Alberti, 1999; Calligaris, 2000; Saggese, 2001; Stevens, 2004, dentre outros).

Desse modo, tendo como base o que nomeamos tensão entre "determinismo da infância" e "contingência adolescente", buscamos apreender como Freud articula a puberdade com o momento de irrupção da neurose ao longo de sua obra, enfatizando, pois, seus principais conceitos, problematizações e deslocamentos teóricos. Afinal, haveria uma especificidade desse momento no âmbito de formação da neurose? O texto freudiano nos permite pensar na emergência do "novo", ou seja, de algo que escapa às determinações primárias, no momento de irrupção da puberdade?

Desta feita, e a fim de melhor elucidarmos tais questões, dentre outras, retomaremos os casos clínicos Dora, Homem dos lobos e Jovem homossexual, problematizando a relevância da puberdade e suas possibilidades no âmbito da constituição subjetiva. Nesse ponto, cabe ressaltar que, longe de formular respostas conclusivas, nosso objetivo é resgatar os pontos principais de impasses, de dúvidas do criador da Psicanálise em relação ao momento de irrupção da puberdade em contraposição ao determinismo da primeira onda sexual no campo das neuroses. Partimos, pois, do pressuposto de que não é apenas a partir dos "ditos" freudianos que podemos apreender seus conceitos, seus fundamentos, mas também a partir do que se deixa ver em suas contradições, interrogações e insistências, construindo hipóteses sobre os problemas que o acossavam.

\section{Primeiras formulações acerca da etiolo- gia das neuroses: puberdade e Teoria do Trauma}

Nas publicações chamadas "pré-psicanalíticas" (Freud, 1886-1889/1996), Freud estava às voltas com a delimitação teórica da histeria: sua história, definição, sintomatologia e tratamento. Assim, desde seus primeiros escritos, ele já apontava para a questão da sexualidade como fator importante na etiologia da histeria, dada a elevada significação psíquica dessa função, principalmente no sexo feminino (Freud, 1888/ 1996). A histeria, nesse momento, era compreendida como uma anomalia constitucional que apresentava, na grande maioria dos casos, seus primeiros sinais no período da adolescência. $\mathrm{O}$ autor admite não ser raro o surgimento da doença em crianças entre os seis e dez anos, porém isso ocorre apenas em casos de "intensa disposição histérica" (Freud, 1888/1996).

Contudo, segundo Freud (1888/1996), "a juventude, dos quinze anos em diante, é o período no qual a neurose histérica, na maioria das vezes, se mostra ativa em pessoas do sexo feminino" (p. 88). Tal relação temporal explica-se, nesse momento, pela ideia de que a evolução dos sintomas histéricos exige, pois, um "período de incubação", ou seja, um "período de latência" na qual a causa desencadeante continua a atuar no inconsciente. Nessa perspectiva, inúmeros foram os casos clínicos em que Freud apontou o início da sintomatologia no período da irrupção da puberdade. Dentre eles, podemos destacar aqueles citados nos "Estudos sobre histeria", que ora tratam de uma jovem que sofria de tossis nervosa, ora de uma senhora idosa com ataques de angústia, ou de uma jovem esposa (Freud, 18931895/1996). No caso desta paciente, Freud pontua que

ainda nos primeiros anos de sua adolescência, ela costumava por algum tempo ser encontrada todas as manhãs num estado de estupor, com os membros rígidos, a boca aberta e a língua para fora; e agora, mais uma vez, estava sofrendo, ao despertar, de acessos que eram semelhantes, embora não tão graves. (Freud, 1893/1996, p. 288)

Porém, embora admita a regularidade com que tais fenômenos ocorram na puberdade, Freud começa a direcionar as causas da doença para o momento da infância. $\mathrm{Na}$ análise da jovem esposa, por exemplo, chega a afirmarlhe, desde o início, que seus sintomas estavam relacionados com as causas de seu estado de infância. (Freud, 1893/1996)

Em "Etiologia da histeria", conferência proferida ante a verein fur Psychiatrie und Neurologie, Freud fundamentou as bases do que seria a sua "teoria do trauma", que vigorou até o ano de 1897, marco na Psicanálise por representar o descrédito de Freud à "teoria da sedução". As causas da histeria eram, assim, determinadas "por certas experiências do paciente que atuaram de forma traumática e que são reproduzidas na vida psíquica por meio de símbolos mnêmicos" (Freud, 1896b/1996, p. 190). Segundo suas próprias palavras,

É verdade que essas experiências, descobertas com tanta dificuldade e extraídas de todo o material mnêmico, e que pareceriam ser as experiências traumáticas máximas, têm em comum as duas características de serem sexuais e ocorrerem na puberdade; mas em todos os outros aspectos, elas diferem muito entre si, tanto em espécie como em importância. (Freud, 1896b/1996, p. 197) 
Cabe ressaltar que a puberdade, naquele período, era vista por Freud como o momento único em que emergia a sexualidade humana. Porém, ao longo de sua formulação, vai retrocedendo à infância, admitindo experiências de cunho sexual nesse período, mesmo que sob a estimulação de um adulto. Em "Etiologia da histeria", Freud aponta para a necessidade de prosseguir suas investigações acerca dos determinantes dos sintomas, retomando momentos anteriores, mais especificamente ligados à infância. Diante disso, pontua que "para a felicidade de nossa explicação, algumas dessas experiências sexuais da puberdade mostram mais uma insuficiência que é a conta certa para nos estimular a prosseguir em nosso trabalho analítico" (Freud, 1896b/1996, p. 199). Desta feita,

Parecia óbvio, portanto, dizer a nós mesmos que deveríamos procurar os determinantes desses sintomas em outras experiências - em experiências que retrocedessem ainda mais - e que deveríamos, pela segunda vez, seguir a salvadora noção que já nos levara das primeiras cenas traumáticas às cadeias de lembranças por trás delas. (Freud, 1896b/1996, p. 198)

Dessa forma, segundo Freud, as experiências sexuais infantis constituem precondição fundamental da histeria e são elas que criam sintomas histéricos, porém "não o fazem de imediato, permanecendo, inicialmente sem efeito e só exercendo uma ação patogênica depois, ao serem despertadas, após a puberdade, sob a forma de lembranças inconscientes" (Freud, 1896b/1996, p. 207). Entretanto, mesmo construindo as bases para um determinismo da infância na etiologia das neuroses, Freud não deixa de considerar a importância das experiências contemporâneas à puberdade, apontando que "todos os casos de histeria apresentam sintomas determinados não por experiências infantis, mas por experiências posteriores, muitas vezes recentes" (Freud, 1896b/1996, p. 209).

Nesse sentido e partindo desse pressuposto, podemos interrogar qual a natureza de tais experiências posteriores contemporâneas à puberdade que as tornam capazes de reativar a cena traumática. Enfim, qual a função da experiência posterior, contingência adolescente, na formação do sintoma? Elas são importantes apenas na medida em que evidenciam o trauma infantil ou podem elas mesmas funcionar como um novo trauma, excesso que irrompe em uma série de sintomatologias ou que faz série com o trauma infantil?

Quanto a isso, o autor argumenta que a excitação sexual durante a infância não é capaz de gerar uma sintomatologia por si só, uma vez que "a excitação sexual precoce surte pouco ou nenhum efeito na época”. Porém, algo é mantido, seu traço psíquico, que, a posteriori, deixará marcas (Freud, 1896d/1996, p. 152). Desta feita, apenas

Mais tarde, na puberdade, quando as reações dos órgãos sexuais se desenvolvem num nível desproporcional a seu estado infantil, esse traço psíquico inconsciente é de algum modo despertado. Graças à transformação devida à puberdade, a lembrança exibe um poder que esteve totalmente ausente do próprio evento. A lembrança atua como se ele fosse um evento contemporâneo. O que acontece é, por assim dizer, a ação póstuma de um trauma sexual. (Freud, 1896d/1996, p. 152)

Podemos inferir, pois, que esta explicação freudiana para o fato de a doença surgir no momento da puberdade deveu-se a sua hipótese de que o sujeito estaria às voltas, pela primeira vez, com a questão da sexualidade. Há, portanto, uma confusão entre a sexualidade e a genitalidade. Assim, a lembrança do trauma é reativada e ganha um aspecto de atualidade porque, conforme o próprio autor nos aponta no "Projeto para uma psicologia científica", "nenhuma experiência sexual produz qualquer efeito enquanto o sujeito ignora toda e qualquer sensação sexual - quer dizer, em geral, antes do início da puberdade" (Freud, 1900/1996, p. 385). Dessa forma, conforme aponta Gutierra (2003),

A puberdade e o consequente despertar da sexualidade, apesar de não ser mais considerada a causa necessária das neuroses em função do seu excedente energético, continua tendo um lugar de destaque nesse momento inicial da teorização freudiana. Agora seu lugar é o de potencializar os traços de experiências sexuais infantis. (p. 31)

Porém, mesmo priorizando a justificativa principal de que a puberdade é o momento de surgimento da sexualidade humana, Freud aponta, ainda timidamente, para algo específico da puberdade, que permite inferir algo mais: um "excesso original", que tornam os adolescentes vivazes, inteligentes e resistentes à monotonia. Em "Predisposição inata - Desenvolvimento da histeria" (Freud, 18931895/1996, p. 258), trabalho realizado em conjunto com J. Breuer, Freud pontua que

Durante o desenvolvimento na puberdade e em consequência dele, esse excesso original é complementado pelo poderoso aumento da excitação que decorre do despertar da sexualidade, das glândulas sexuais. A partir daí há uma quantidade excedente de energia nervosa livre disponível para a produção de fenômenos patológicos. (Freud, 1893-1895/1996, p. 258)

Desse modo, tal "excesso original", aliado e diferenciado do aumento considerável da excitação sexual, gera desprazer no psiquismo, ativando, pois, o processo de defesa e a formação dos sintomas. Os autores acreditavam que o próprio despertar da sexualidade gerava uma predisposição à histeria, já que possibilitava uma excitabilidade maior do sistema nervoso. Porém, mesmo diante de tal pressuposto, os autores problematizam que é 
Tão frequente vermos adolescentes anteriormente sadios, embora excitáveis, adoecerem de histeria durante a puberdade, que devemos perguntar a nós mesmos se esse processo não poderia criar uma predisposição para a histeria quando ela não está inatamente presente. E de qualquer modo, devemos atribuir a ela mais do que uma simples elevação da quantidade de excitação. (Freud, 1893-1895/1996, p. 262)

Portanto, desde essa época, Freud já se interrogava sobre a recorrência do aparecimento dos primeiros sintomas das neuroses no momento da puberdade. Afinal, o que a puberdade traria de disruptivo no processo de formação da neurose, que nos permitiria, em alguma medida, compreender sua formação e o surgimento dos sintomas? Em que medida a irrupção da puberdade e seus acontecimentos poderia trazer algo de próprio e específico na constituição do sintoma, além de um mero ativador do trauma infantil?

Desde a "Carta 75" (Freud, 1897c/1996), o autor parece tentar apreender as peculiaridades do processo da puberdade, só localizando aí a emergência da diferença entre os sexos: quando as meninas são acometidas por uma repugnância sexual não-neurótica, e os meninos, pela libido. Desse modo, é possível apreender uma diferenciação no recalcamento nos diferentes sexos, sendo que nas meninas destaca-se o fato de a repugnância sexual ocorrer mais cedo. A consequência de tais descobertas foi a ideia de que

A escolha da neurose (a decisão quanto à emergência da histeria, da neurose obsessiva, ou da paranóia) depende da natureza da onda de desenvolvimento (ou seja, a natureza cronológica) que possibilita a ocorrência do recalcamento - isto é, que transforma uma fonte de prazer interno em uma fonte de repugnância interna. (Freud, 1897c/1996, p. 321)

Nesse momento, pois, o que estava em jogo na etiologia das neuroses não era a ocasião em que o recalque se fazia presente, mas os períodos em que ocorriam o evento e a natureza do mesmo, capaz de dar origem à defesa (Freud, 1896a/1996). Nessa perspectiva, as diferentes neuroses apresentam quesitos cronológicos particulares e apareciam em determinados momentos. Dentre as neuroses, apenas a histeria podia surgir também em um período mais precoce, dos oito aos dez anos; as demais neuroses, dentre ela a neurose obsessiva e a paranoia, irrompiam em um período correspondente a pré-puberdade ou a puberdade.

Desse modo, é curiosa a recorrência com que Freud aponta o fator temporal da puberdade como momento de irrupção da doença. Ela é, nessa perspectiva, "vista como um efeito orgânico que gera um efeito psíquico - a mudança física gera um excesso de libido, cuja carga potencializa lembranças infantis e exige um posicionamento no campo da sexualidade" (Gutierra, 2003, p. 32).
Por conseguinte, no caso clínico "Dora" (1905[1901]/1996), Freud demonstra que a paciente, desde os oitos anos de idade, já apresentava sintomas neuróticos. Nesse período, sofria de dispnéia crônica com acessos ocasionais agudos, surgida após uma primeira excursão pelas montanhas e diagnosticada, desde já, como distúrbio nervoso. Aos doze anos, apresentava dores de cabeça unilaterais seguidas de tosse nervosa, sintomas que foram se tornando independentes. A tosse prolongava-se por várias semanas, podendo ser acompanhadas pela perda da voz, manifestações que eram tratadas com hidroterapia e aplicação local de eletricidade, costume da época (Freud, $1905[1901] / 1996$, p. 32). Freud, nesse momento, pontua que

Desde então tenho visto inúmeros casos de histeria, ocupando-me de cada um por vários dias ou anos, e em nenhum deles deixei de descobrir as condições psíquicas postuladas nos Estudos, ou seja, o trauma psíquico, o conflito de afetos e, como acrescentei em publicações posteriores, a comoção na esfera sexual. (Freud, 1905[1901]/1996, p. 34)

Nesse sentido, o autor busca, na história clínica da paciente, os determinantes da etiologia da histeria, enfatizando, nesse caso, a aproximação dos pais de Dora com a família K como o fator determinante na constituição dos sintomas posteriores. Freud admite que as propostas amorosas do Sr. K. a Dora, em plena puberdade, e a afronta a sua honra parecem fornecer a ideia do trauma psíquico, conforme foi analisado nos "Estudos sobre histeria" (Freud, 1905[1901]/1996, p. 36). Assim, a famosa "cena do beijo",

Era justamente a situação que, numa mocinha virgem de quatorze anos, despertaria uma nítida sensação de excitação sexual. Mas Dora sentiu naquele momento uma violenta repugnância, livrouse do homem e passou correndo por ele em direção à escada, daí alcançando a porta da rua. (Freud, 1905[1901]/1996, p. 37)

Porém, mesmo apontando para uma experiência na puberdade como delimitadora de um trauma psíquico, Freud demonstra mais uma vez a incompletude dessa teoria, afirmando que não basta apenas localizar o trauma para entender a especificidade do sintoma, para determiná -lo (Freud, 1905[1901]/1996, p. 36). Nessa perspectiva, há que se considerar que alguns dos sintomas já existiam antes do trauma, e remontavam à época da infância, aos oito anos de idade. Portanto, conforme o próprio autor afirma, "se não queremos abandonar a teoria do trauma, devemos retroceder até a infância da moça e buscar ali influências ou impressões que pudessem ter surtido efeito análogo ao de um trauma" (Freud, 1905[1901]/1996, p. 36). Com efeito, mesmo nos casos em que os primeiros sintomas não se tinham instalado na infância, Freud reconstruía a biografia dos pacientes até seus primeiros anos de vida, buscando apreender aí os determinantes da neurose. 


\section{Mudanças teóricas: a teoria da sexualidade infantil e as "conclusões" adolescentes}

O descrédito do autor à chamada "Teoria da sedução" exigiu, pois, uma nova reformulação da teoria da "etiologia das neuroses", apontando para a concepção de "realidade psíquica" e, mais tarde, para a de "Complexo de Édipo", como algo universal e preponderante para a escolha da neurose (Freud, 1897b, 1897d/1996). Desse modo, segundo Freud, já não era mais possível acreditar "em sua neurótica", ou seja, considerar que todas as histéricas foram, em alguma medida, vítimas de abuso sexual na infância (Freud, 1897e/1996). Tais questionamentos levaram o fundador da psicanálise a concluir que a infância também era marcada por experiências sexuais específicas, que, diferentemente de serem ocasionadas pela sedução de um adulto, apontavam para uma estimulação do próprio corpo, o chamado "autoerotismo".

Esse momento representa um marco na teoria psicanalítica, já que circunscreveu a teorização da "sexualidade infantil" e sua importância na causação das neuroses. Destaca-se também, nesse período, uma mudança radical na concepção de puberdade e na importância dada a ela, já que a infância vai sendo trazida cada vez mais para o primeiro plano, passando a ser considerada como o fator determinante e exclusivo na etiologia das neuroses.

Nos "Três ensaios sobre a teoria da sexualidade" (1905/1996), obra de referência sobre o tema, Freud aborda as manifestações sexuais da infância, buscando compreender os processos por que passa a pulsão sexual ao longo de sua constituição. Em acréscimo realizado em 1915, formula as "fases de desenvolvimento da organização sexual", as chamadas: fases "pré-genital" e "genital". O autor considera a primeira delas como o período da organização sexual "em que as zonas genitais ainda não assumiram seu papel preponderante" (Freud, 1905/1996, p. 186). Tal fase da vida sexual infantil é caracterizada pelo fato de ser essencialmente autoerótica (seu objeto encontrar-se no próprio corpo) e de suas pulsões parciais serem inteiramente desvinculadas e independentes entre si na obtenção de prazer.

Dessa forma, as sucessivas "fases" que compõem tal organização pré-genital oral, anal e fálica vão se sucedendo, não como estágios que se concluem totalmente e são substituídos por outros, mas como emaranhado de excitações que deixam resquícios, marcando profundamente a constituição do psiquismo na vida adulta. A chamada fase fálica, introduzida em 1923, é considerada o momento de maior aproximação da organização sexual infantil à do adulto, já que "o interesse nos genitais e em sua atividade adquire uma significação dominante, que está pouco aquém da alcançada na maturidade" (Freud, 1923/1996, p. 158).

Porém, mesmo havendo uma profunda aproximação com a configuração sexual da vida adulta, há uma

2 O conceito de fase genital foi formulado por Freud (1913/1996). diferença primordial que "consiste no fato de que para ambos os sexos somente um órgão genital entra em consideração: o masculino; o que está presente, desta feita, não é uma primazia dos órgãos genitais, mas uma primazia do falo" (Freud, 1923/1996, p. 158). Desta feita, Freud abre caminho para a função simbólica desempenhada pelo pênis, órgão colocado em evidência pelas crianças tanto do sexo masculino quanto o feminino, já que a vagina só é descoberta na época da puberdade.

A puberdade, nesse contexto, é vista como uma fase de conclusão, de fechamento, em que o desfecho do desenvolvimento constitui a chamada vida sexual normal do adulto, marcada pela primazia da genitalidade (Freud, 1905/1996, p. 186). Desse modo, a puberdade é assinalada pela convergência das pulsões parciais da infância sob a égide da genitalidade, última fase da organização sexual. Além do mais, como os primeiros objetos infantis tornamse inutilizáveis pela ação do recalcamento do período da latência, é necessário o processo de uma "segunda" escolha de objeto, mesmo que Freud a considere já determinada pela anterior. Com o declínio do Édipo e a amenização dos alvos sexuais infantis, surgem as "correntes ternas" que fazem referência ao primeiro protótipo de escolha de objeto. Segundo Freud,

A escolha de objeto da época da puberdade tem de renunciar aos objetos infantis e recomeçar com uma corrente sexual. É preciso que haja a confluência da corrente de ternura com a sexual para que o sujeito possa alcançar um dos ideais da vida sexual - a conjugação de todos os desejos num único objeto. (Freud, 1905/1996, p. 189)

Nesse sentido, como o próprio Freud pontua, tal convergência da "corrente terna" e a "corrente sexual" representa um processo de passagem, uma "travessia de um túnel perfurado desde ambas as extremidades" (Freud, 1905/1996, p. 196) Dentro desse viés de análise, conforme esclarecem Viola e Vorcaro (2012),

$\mathrm{Na}$ "engenharia" freudiana, ao abrirem caminho para a sexualidade supostamente "adulta", duas correntes distintas perfuram diferentes túneis, partindo de diferentes lugares e em distintas direções, e só vão se cruzar ao acaso, se porventura seus caminhos se encontrarem na opacidade subterrânea, por pura contingência. (p. 8)

Além do mais, o próprio Freud parece admitir a possibilidade de uma não confluência, ou seja, de uma não junção das duas correntes, a terna e a sexual no momento da puberdade, demarcando a "impossibilidade de se alcançar um dos ideais da vida sexual - a conjugação de todos os desejos num único objeto" (Freud, 1905/1996, p. 189). Nessa perspectiva, se a puberdade é descrita por Freud como um momento de conclusão de algo que vinha se delimitando na infância, a metáfora acima não deixa de 
trazer à tona os desencontros, a impossibilidade de uma conclusão que qualifique uma vida sexual dita "normal". Dessa forma, não estaria Freud colocando em evidência a possibilidade de inúmeros desarranjos na constituição da chamada vida sexual adulta, permitindo inferir a emergência de algo novo, ou seja, diferente do que vinha se delimitando, se constituindo desde a infância?

Cabe ressaltar que a sexualidade humana constitui-se em "dois tempos", dentre os quais há o "período de latência", momento marcado por uma longa interrupção que posterga o desenvolvimento da pulsão sexual até a puberdade (Freud, 1911/1996), marcado pela presença das "formações reativas", da "sublimação" e da "formação da fantasia". Cabe destacar que as primeiras se constituem pela existência de uma "ambivalência pulsional", que delimita uma atitude ou um hábito oposto a um desejo recalcado. Segundo Laplanche e Pontalis, a formação reativa qualifica-se por ser um contrainvestimento permanente, já que

o sujeito que elaborou formações reativas não desenvolve certos mecanismos de defesa para empregar diante da ameaça de um perigo pulsional; mudou a estrutura de sua personalidade como se esse perigo estivesse sempre presente, para estar pronto em qualquer momento em que surgir. (Laplanche \& Pontalis, 2004, p. 201)

Além disso, elas podem assumir, do ponto de vista clínico, "um valor sintomático no que oferecem de rígido, de forçado, de compulsivo, pelos seus fracassos acidentais, pelo fato de levarem, às vezes diretamente, a um resultado oposto ao que é conscientemente visado" (Laplanche \& Pontalis, 2004, p. 200).

Outra função importante do "período de latência" é o desvio das pulsões sexuais para outros fins mais elevados, tais como a aquisição do conhecimento e a construção de aspirações éticas, típicas do processo de sublimação (Freud, 1905-1919/1996). Porém, segundo Freud, esse processo não é generalizado, já que alguma atividade sexual na latência é sempre preservada até a irrupção acentuada da pulsão sexual na puberdade (Freud, 1905/1996).

Cabe ressaltar que a latência inicia-se a partir da renúncia do menino ao amor incestuoso devido à ameaça da castração, período marcado por intensa angústia. Nos termos de Viola e Vorcaro, "trata-se de uma calmaria apenas de superfície, a encobrir as águas tortuosas de uma angústia pungente e de um supereu em construção" (Viola \& Vorcaro, 2012, p. 5). E é a partir da ação desse supereu que a formação reativa e as inibições à realização da pulsão sexual emergem e se fundamentam. Nesse caso, podemos inferir que o período de latência promove exigências à pulsão sexual, gerando torções que colocam em xeque sua satisfação imediata, exigindo, pois, "formações de compromissos". Dessa forma, qual a consequência da irrupção da puberdade, processo que reafirma a força da pulsão sexual, nos direcionamentos da latência? Por que tal período é marcado pelo aparecimento dos primeiros sintomas da neurose?

A fim de compreender a existência de um "período de latência" na sexualidade humana, Freud lança a hipótese de que "algo momentoso deve ter ocorrido nas vicissitudes da espécie humana que deixou para trás essa interrupção no desenvolvimento sexual do indivíduo como um precipitado histórico" (Freud, 1926/1996, p. 151). Nesta medida, o autor lança mão do filogenético para entender esse período de "calmaria", apontando para um acontecimento de ordem mítica. Porém a questão que se coloca aqui é: qual a função dessa interrupção na organização da pulsão sexual no que se refere aos direcionamentos da puberdade? Enfim, a característica primordial da sexualidade como que fundamentada em dois tempos permite-nos corroborar a hipótese da impossibilidade de uma "conclusão", de uma junção das pulsões sexuais sob a égide da genitalidade? A puberdade, nesse caso, não poderia emergir como algo que coloca em xeque os determinantes infantis?

Outro ponto importante de ser destacado é a relação da latência com a construção da fantasia. Para Freud, a escolha objetal realiza-se em "duas ondas"; sendo a primeira de ocorrência na infância, marcada pelos primeiros objetos de amor, os pais, e a segunda, concretizada na época da puberdade. Em "Formulações sobre os dois princípios do funcionamento mental", Freud (1911/1996) afirma que a primeira escolha de objeto, tão logo se inicia, é interrompida pelo período de latência. De modo geral, ainda nesse momento, a relação do sujeito com o objeto se apresenta ainda no âmbito da fantasia, podendo se concretizar apenas na época da puberdade, quando se faz necessária a convergência das correntes terna e sensual em um mesmo objeto.

Portanto, podemos inferir que Freud, ao tratar da "escolha de objeto" como em duas ondas, momentos separados logicamente, vai desconstruindo a ideia de uma organização linear, ideal, que configuraria a dita vida sexual "normal" do adulto, apontando para o "inédito", para algo que escapa ao previsível. Assim, não estaria a puberdade ligada a esse elemento disruptivo? Afinal, se a latência é o período de construção de um saber sobre o objeto a partir da fantasia, quais as consequências da irrupção da puberdade, momento marcado pela possibilidade de concretização das mesmas?

Da mesma forma, cabe destacar que a infância para Freud é "uma espécie de organização frouxa", que deve ser consolidada na puberdade, fase final do desenvolvimento psicossexual (Freud, 1915-1916/1996, p. 331). Para ele, nesse momento de sua formulação, a vida sexual não surge na adolescência como algo acabado, mas como fruto de um processo de desenvolvimento composto por sucessivas fases, diferentes entre si, cuja evolução repete-se várias vezes (Freud, 1915-1916/2006, p. 332).

Dessa forma, é evidente o quanto a infância adquire importância central na obra de Freud, sobretudo no que se refere ao direcionamento e às conclusões da puberdade. Percebemos, pois, que o encontro com o objeto que deverá ser concluído na puberdade está orientado, de alguma 
forma, pelo primeiro protótipo da escolha objetal da infância. Porém, a ideia que se mantém em toda sua formulação é de que puberdade é o momento de manifestação das neuroses a partir das solicitações da vida sexual.

No caso clínico "Homem dos lobos", Freud (1918 [1914]/1996) retrocede até uma neurose infantil, mas também descreve o surgimento de uma neurose posterior durante a puberdade, mesmo que esse não seja o foco de seu interesse. Em sua descrição da história clínica, o autor pontua que a infância do paciente foi marcada por um grave distúrbio neurótico, caracterizado por uma fobia e uma neurose obsessiva, cujos sintomas se interromperam aos dez anos, irrompendo novamente apenas na puberdade (quando contraiu uma gonorreia infecciosa).

Freud afirma que o início da neurose ocorre quando o paciente contava com um ano e meio, marcado por sintomas de "falta de apetite". Nessa perspectiva, a cena da governanta Grusha, ajoelhada no chão varrendo a casa com uma vassoura curta, foi primordial por fazer referência à cena primária, à relação sexual dos pais. Ele ressalta que nessa época o órgão genital masculino já era supervalorizado pela criança, por isso a reação da criança à cena (ereção) representa uma identificação com o pai. Foi somente a ameaça de castração que fez a "organização genital" sucumbir e regredir à organização anal sádica. Dentro desse viés de análise, o sonho com os lobos atuou não apenas como um evento recente, mas como um novo trauma, na medida em que fez operar a cena primária (Freud, 1918[1914]/1996, p. 116). Assim, a fobia representava uma forma do paciente se defender da corrente homossexual. Já a relação com o pai e a influência religiosa produziram o início de uma neurose obsessiva, que se manifestava a partir de ruminações em torno da figura de Cristo e sua relação com seu pai (Freud, 1915-1916/1996).

O diferencial desse caso, que possibilitou sua eleição pelo autor, relaciona-se ao fato de que a neurose adulta foi precedida por outra ainda nos primeiros anos da infância, fundamentando as bases do que seria o "determinismo do período da infância" na etiologia das neuroses. Freud afirma categoricamente ser "de opinião que a influência da infância se faz sentir na situação com que se inicia a formação de uma neurose, de vez que desempenha um papel decisivo na ação de determinar se, e em que ponto, o indivíduo deixa de dominar os verdadeiros problemas da vida" (Freud, 1918[1914]/1996, p. 64).

A neurose, até esse momento considerada em seu cunho regressivo, num retorno da libido a pontos de fixação pregressos ocasionados por um conflito, tem suas causas retomadas por Freud, acrescentando então que há também outra vertente que "a partir das impressões da infância, opera numa direção futura, que aponta um caminho para a libido que se retrai diante da vida e que torna possível compreender a de outro modo inexplicável regressão à infância" (Freud, 1918[1914]/1996, p. 63). Assim, o caso do Homem dos Lobos é considerado por Freud como afeito à segunda vertente, posto que é a neurose infantil que direciona os rumos da libido, determinando a neurose na vida adulta. A fim de embasar sua tese, ele afirma que "a mobilidade das catexias mentais diminui consideravelmente a medida que a idade avança" (Freud, 1918[1914]/1996, p. 122). Nessa medida,

toda neurose em um adulto é construída sobre uma neurose que ocorreu em sua infância, mas que não foi grave o bastante para chamar a atenção e ser reconhecida como tal. Essa objeção serve apenas para enfatizar a importância teórica do papel que as neuroses infantis desempenhariam, no nosso ponto de vista, nos distúrbios posteriores que tratamos como neuroses e procuramos atribuir inteiramente aos efeitos da vida adulta. (Freud, $1918[1914] / 199$, p. 106)

Nesse ponto, podemos inferir que Freud leva o determinismo da infância às últimas consequências, não se atendo aos detalhes da história da neurose posterior surgida na puberdade, fornecendo apenas "algumas informações breves” (Freud, 1918[1914]/1996, p. 123). Aponta que a irrupção da puberdade fez surgir no paciente uma corrente masculina sensual que estava eminentemente ligada à cena de Grusha, que marcou profundamente sua escolha objetal na puberdade. Desta feita, essa segunda escolha de objeto se caracterizou por uma substituição da "postura de Grusha" pela sua "posição social".

Dentro desse viés de análise, Freud ressalta que o paciente sempre se interessava por mulheres de baixa classe social, o que revelava seu gosto em aviltar o objeto de amor. O autor afirma que a situação do homem dos lobos resumia-se na seguinte fórmula: "sua infância fora marcada por uma oscilação entre atividade e passividade, a puberdade por um esforço de masculinidade, e o período que se seguiu à sua doença, por uma luta pelo objeto dos seus desejos masculinos" (Freud, 1918[1914]/1996, p. 123). Freud admite que a causa que precipitou a neurose adulta coloca em evidência uma lacuna teórica, à medida que não se enquadra em nenhum dos tipos que descreveu como casos especiais de frustração (Freud, 1918[1914]/1996).

A doença posterior do paciente "sucumbiu depois que uma afecção orgânica dos genitais havia reavivado o medo da castração, destruído seu narcisismo, e o compelira a abandonar a esperança de ser pessoalmente favorecido pelo destino" (Freud, 1918[1914]/1996, p. 124). Assim, Freud, mesmo considerando que haja algum ponto inexplicável nesse processo, se propõe a justificar a irrupção da doença posterior a puberdade apenas com referência às vivências infantis, não considerando nem problematizando a possível influência da puberdade nesse processo. Seria apenas uma mera questão do "acaso" o fato de a doença posterior surgir na puberdade? Devemos considerar, pois, que a neurose do paciente se manifestou em dois tempos separados por um período de interrupção dos sintomas quando ele contava com dez anos. Essa interrupção poderia coincidir com o período de latência? Quais as consequências do despertar das pulsões sensuais na época da 
puberdade e o possível encontro com o objeto? Afinal, devemos considerar que o encontro do jovem com o objeto de amor pode ter sido de um tanto quanto traumático, uma vez que teve como consequência a gonorreia.

Enfim, é evidente o esforço de Freud em demonstrar, na maioria de seus casos, como a neurose infantil delimita e determina a neurose da vida adulta, destacando cada vez mais a função da infância no processo de etiologia das neuroses. Desse modo, ao mesmo tempo em que Freud considera que as reedições e conclusões que acontecem na puberdade já estão determinadas na infância, ele também apresenta pontuações que permitem inferir a existência de algo novo, ou seja, de uma resposta que foge, de certa forma, ao que fora traçado na infância. Portanto, "uma predeterminação infantil é colocada à prova no tempo da puberdade, quando o sujeito terá de dar conta do encontro com o outro sexo. Daí afirmar que também é um tempo passível de trazer algo novo, de permitir novos rearranjos" (Gutierra, 2003, p. 37).

Dentro desse viés de análise, o caso clínico da jovem homossexual (1920) destaca-se também por evidenciar como a presença de acontecimentos na puberdade, momento da revivescência edípica, pode apontar para novos rumos, novas possibilidades antes insuspeitas. Assim, a inexistência de um trauma aparente nos primeiros anos de vida da jovem interrogou o próprio Freud, uma vez que ele se esforçava por apreender os percalços sofridos por ela em sua infância. Pontua então que a afeição da jovem, aos treze anos, pelas crianças pequenas, substituída mais tarde pela paixão pelas jovens mães, estava relacionada com um acontecimento na puberdade, o nascimento de um terceiro irmão quando ela contava com dezesseis anos. Nesse caso, a revivescência edípica durante a puberdade fez reativar o desejo da jovem de ter um filho com o pai, porém a gravidez da mãe nesse período a colocou diante da impossibilidade dessa concretização, marcando um profundo desapontamento que direcionará os rumos de sua escolha objetal.

Desse modo, "furiosamente ressentida e amargurada, afastou-se completamente do pai e dos homens. Passado esse primeiro revés, abjurou de sua feminilidade e procurou outro objetivo para sua libido" (Freud, 1920/1996, p. 169). O autor, mesmo pontuando que a escolha objetal coloca em evidência o aspecto da bissexualidade do ser humano, parece se espantar com o aspecto temporal da mesma, afinal,

Como, porém, devemos compreender o fato de ter sido precisamente o nascimento de uma criança, chegada à família extemporaneamente (numa ocasião em que a própria jovem estava madura e com intensos desejos próprios), que a levou a aplicar sua ternura apaixonada à mulher que dera à luz essa criança, isto é, à sua própria mãe, e expressar esse sentimento para com um substituto materno? (Freud, 1920/1996, p. 169)
Dessa forma, podemos nos perguntar se o nascimento desse irmão no momento da irrupção da puberdade pôde redirecionar os rumos de algo que vinha se constituindo desde a infância. Tal questionamento, por sua vez, coloca em evidência a possibilidade do "novo" na puberdade, em contraposição ao determinismo da infância. Nesse ponto, é importante ressaltar que o próprio Freud parece se questionar acerca de tal possibilidade, mesmo que, ao final desse relato, ele se esforce por apreender elementos que mostrem a pré-determinação da infância (Freud, 1920/1996, p. 180).

Freud pontua que o deslocamento da libido é um fenômeno bastante comum e ocorre principalmente na infância; porém, ao analisar o caso referido, o autor inquietase pelo fato dessa inversão ter ocorrido nos primeiros anos da puberdade. Desse modo, conforme ele pontua, "com nossa paciente, que deveras não era neurótica, realizaramse (deslocamentos da libido) nos primeiros anos seguintes à puberdade, embora por casualidade .... Algum dia, talvez, esse fator temporal se revele de grande importância" (Freud, 1920/1996, p. 170, itálicos nossos). ${ }^{3}$

Percebemos, portanto, que Freud inquieta-se com esse fator temporal, mostrando, mesmo que esse pareça não ser seu foco, que há algo em jogo na irrupção da puberdade. Contudo, ao longo da análise do referido caso, ele mostra-se resistente a tal questionamento, buscando na infância da paciente elementos que determinassem, de alguma forma, sua predisposição à homossexualidade, confirmando mais uma vez sua teoria de que tal deslocamento da libido ocorre invariavelmente na infância.

\section{Considerações finais}

Conforme buscamos delinear nas páginas anteriores, a obra freudiana traz questões importantes acerca do tema da puberdade. Freud não se apropriou do conceito de adolescência em sua obra, não se preocupando em delimitá-lo, circunscrevê-lo dentro do arcabouço teórico da Psicanálise. Raras são as vezes que ele utiliza tal termo, quando muito relacionado a uma faixa etária, fase do desenvolvimento que se coloca entre a infância e a idade adulta. Entretanto, o olhar de Freud insiste em focalizar a questão da irrupção da puberdade, abordando-a sob diferentes ângulos ao longo de sua teorização.

Em sua primeira conceituação acerca do tema, a questão da puberdade ganha enfoque privilegiado, sendo associada ao momento de emergência das neuroses; devido à própria irrupção patológica, que traria um aumento da excitação, dado pelo surgimento da sexualidade. Porém, o que podemos inferir é que, mesmo acreditando que a sexualidade humana emergia apenas nesse momento, Freud traz elementos que colocam em evidência algo específico

3 É importante destacar que a citação se encontra em uma nota de rodapé da página 170, o que nos permite inferir, de certa forma, o pouco destaque dado pelo autor no que se relaciona à argumentação apresentada no texto. 
da puberdade. Desse modo, ele diferencia a excitação oriunda da emergência da sexualidade em relação a um "excesso original", próprio dos adolescentes, que supostamente explicaria uma predisposição à neurose.

Esse ponto é importante porque nos permite pensar na especificidade da puberdade dentro do âmbito das formações das neuroses. Afinal, o que a puberdade traria de tão disruptivo a ponto de ser descrita como o momento de aparecimento das patologias? De fato, conforme é discutido ao longo do texto, o próprio Freud antecipa questões cruciais acerca da adolescência como momento de emergência das neuroses, mesmo que, na maioria das vezes, não se permita aprofundá-las.

Por conseguinte, com a descoberta da sexualidade infantil, a teorização acerca da emergência da puberdade vai sendo posta em segundo plano, apontando apenas para uma fase de conclusão do desenvolvimento psicossexual, iniciado na infância. Contudo, o que podemos perceber é que Freud, mesmo imbuído do exercício de comprovar sua hipótese de um determinismo dos acontecimentos da infância sobre a constituição da neurose posterior, não deixa de apontar para algo novo, inédito, com a emergência da puberdade. Isso pode ser percebido na própria definição de uma sexualidade em dois tempos, separada pelo período de latência, pela hibernação da pulsão sexual.

Além disso, a própria escolha de objeto posterior típica do período da puberdade, mesmo trazendo as marcas da infância, sofrem novas variações, dada a necessidade da impossível confluência almejada das correntes terna e sensual, que se dá a partir do encontro com o objeto. Assim, a concepção de uma sexualidade linear, normal, marcada pela primazia da genitalidade vai sendo deixada de lado, abrindo caminho para se pensar nas falhas, desencontros que podem emergir nesse processo.

Ao mesmo tempo, os casos clínicos, além de colocar em evidência a importância da infância na formação da neurose, permite-nos também inferir como a emergência da puberdade gera percalços, fato que inquietou o próprio Freud, mesmo que ele não tenha se debruçado sobre o tema de forma aprofundada. Por fim, mesmo às voltas com a necessidade de comprovar a existência da sexualidade infantil e a importância dos acontecimentos da infância, podemos concluir que Freud trouxe importantes contribuições para se pensar em uma especificidade da puberdade no âmbito da formação da neurose. Assim, o tema da puberdade irrompe nas entrelinhas do texto freudiano, em seus questionamentos, seus impasses, permitindo-nos evidenciar sua teorização acerca do tema. Tal exercício de apontamento coloca em evidência questões importantes que nos permitem não só trazer o tema novamente à cena, numa de suas primeiras abordagens, mas também circunscrever elementos que possam emergir na estrutura psíquica no momento da puberdade, delimitando-a, solidarizando-a, possibilitando, assim, novas problematizações para a clínica com adolescentes.

\title{
Freudian concepts on the irruption of puberty and the etiology of neuroses
}

\begin{abstract}
This work aims to outline the nuance of the concept of puberty throughout Sigmund Freud's studies. We intend to understand how Freud, based on the interface between 'determinism of childhood period' and 'teenagers contingency', articulates puberty in relation to the irruption of neurosis. We deal with the relevance of the 'latency period' and also with the assumption of sexuality 'in two stages', according to the understanding about puberty and its possibilities for the constitution of the subject. We use as a methodological resource some of the main clinical cases analyzed by Freud such as Dora, The WolfMan and The Young Homosexual Woman. In this way, our purpose is to stablish the discussion on the relevance of the irruption of puberty, its possibilities and obstacles in the causation/manifestation of any neurosis. We realized that Freud, while not taking this issue as the focus of his research, explores it throughout his studies, allowing us to infer and discuss his point of views about this theme.
\end{abstract}

Keywords: etiology of neurosis, irruption of puberty, childhood, clinical cases.

\section{Concepts freudiens sur l'irruption de la puberté et l'étiologie des névroses}

Résumé: Ce travail vise à décrire la nuance du concept de la puberté à travers les études de Sigmund Freud. Nous avons l'intention de comprendre comment Freud, basé sur l'interface entre le «déterminisme de la période de l'enfance» et la «contingence adolescent», articule la puberté par rapport à l'irruption de la névrose. Nous nous occupons de la pertinence de la «période de latence» et également avec l'hypothèse d'une sexualité «en deux étapes», selon la compréhension de la puberté et de ses possibilités pour la constitution du sujet. Nous utilisons les ressources méthodologiques de certains des principaux cas cliniques analysés par Freud comme Dora, L'homme-aux-loups et $L a$ Jeune Homosexuelle. De cette façon, nous avons le but de discuter de la pertinence de l'irruption de la puberté, de ses possibilités et les obstacles dans la causalité/ manifestation d'une névrose. Nous avons réalisé que Freud, tout en ne prenant pas cette question comme l'objet de ses recherches, il l'a explorée au long de ses études, ce qui nous permet de considérer et de discuter de son point de vue sur ce thème. 
Mots-clés: létiologie des névroses, l'irruption de la puberté, l'enfance, les cas cliniques.

\section{Conceptos freudianos sobre la irrupción de la pubertad y la etiología de las neurosis}

Resumen: Este trabajo tiene como objetivo captar los matices del concepto de la pubertad a lo largo de la obra freudiana. Buscamos entender cómo Freud, basado en la relación entre "determinismo del período de la infancia" y "contingencia adolescente", articula la pubertad al momento de la irrupción de la neurosis. Problematizaremos la relevancia del "período de latencia" y del presupuesto de una sexualidad "en dos momentos" en la comprensión de la pubertad y de sus posibilidades en el ámbito de la constitución del sujeto. Utilizaremos como recurso metodológico el rescate de los principales casos clínicos de Freud, entre ellos, Dora, el Hombre de los Lobos y La joven homosexual, buscando captar la relevancia del momento de irrupción de la pubertad, sus posibilidades, sus contratiempos en la causación / manifestación de la neurosis. Notamos que Freud, si bien no toma el asunto como el foco de su investigación, lo toca a lo largo de su trabajo, lo que nos permite inferir y discutir sus puntos de vista sobre el tema.

Palabras clave: etiología de la neurosis, irrupción de la pubertad, infancia, casos clínicos.

\section{Referências}

Aberastury, A. (1983). Adolescência. Porto Alegre, RS: Artes Médicas.

Alberti, S. (1999). Esse sujeito adolescente. Rio de Janeiro, RJ: Rios Ambiciosos.

Blos, P. (1986). Adolescência: uma interpretação psicanalitica. São Paulo, SP: Martins Fontes.

Braconnier, A. (1985). Ruptures et séparations. Adolescence, $3(1), 5-19$.

Calligaris, C. (2000). A adolescência. São Paulo, SP: Publifolha.

Freud, A. (1946). Psicoanalisis del nino. Buenos Aires: Iman.

Freud, S. (1996). Parte II. Psicopatologia. In S. Freud, Edição standard brasileira das obras psicológicas completas de Sigmund Freud (J. Salomão, trad., Vol. 1, pp. 401- 443). Rio de Janeiro, RJ: Imago. (Trabalho original publicado em 1886-1889)

Freud, S. (1996). Histeria. In S. Freud, Edição standard brasileira das obras psicológicas completas de Sigmund Freud(J. Salomão, trad., Vol. 1, pp. 75-94). Rio de Janeiro, RJ: Imago. (Trabalho original publicado em 1888)

Freud, S. (1996). Predisposição inata-desenvolvimento da histeria. In Edição standard brasileira das obras psicológicas completas de Sigmund Freud (J. Salomão, trad., Vol. 2, pp. 258-268). Rio de Janeiro, RJ: Imago. (Trabalho original publicado em 1893-1895)

Freud, S. (1996). Rascunho B. A etiologia das neuroses. In S. Freud, Edição standard brasileira das obras psicológicas completas de Sigmund Freud (J. Salomão, trad. Vol. 1, pp. 223-229). Rio de Janeiro, RJ: Imago. (Trabalho original publicado em 1893)

Freud, S. (1996). Pensamento e realidade. In S. Freud, Edição standard brasileira das obras psicológicas completas de Sigmund Freud (J. Salomão, trad. Vol. 1, pp. 385-390). Rio de Janeiro, RJ: Imago. (Trabalho original publicado em 1950 [1895])
Freud, S. (1996). Carta 46. In S. Freud, Edição standard brasileira das obras psicológicas completas de Sigmund Freud (J. Salomão, trad. Vol. 1, pp. 276-280). Rio de Janeiro, RJ: Imago. (Trabalho original publicado em 1896a)

Freud, S. (1996). A Etiologia da histeria. In S. Freud, Edição standard brasileira das obras psicológicas completas de Sigmund Freud (J. Salomão, trad., Vol. 3, pp. 187-215). Rio de Janeiro, RJ: Imago. (Trabalho original publicado em 1896b)

Freud, S. (1996). Rascunho K. As neuroses de defesa. In S. Freud, Edição standard brasileira das obras psicológicas completas de Sigmund Freud (J. Salomão, trad., Vol. 1, pp. 267-276) Rio de Janeiro, RJ: Imago. (Trabalho original publicado em 1896c)

Freud, S. (1996). A hereditariedade e a etiologia das neuroses. In S. Freud, Edição standard brasileira das obras psicológicas completas de Sigmund Freud (J. Salomão, trad., Vol. 3, pp. 141-155). Rio de Janeiro: Imago. (Trabalho original publicado em 1896d)

Freud, S. (1996). Carta 70. In S. Freud, Edição standard brasileira das obras psicológicas completas de Sigmund Freud (J. Salomão, trad., Vol. 1, pp. 311-314). Rio de Janeiro, RJ: Imago. (Trabalho original publicado em 1897b)

Freud, S. (1996). Carta 75. In S. Freud, Edição standard brasileira das obras psicológicas completas de Sigmund Freud (J. Salomão, trad., Vol. 1, pp. 318-322). Rio de Janeiro, RJ: Imago. (Trabalho original publicado em 1897c)

Freud, S. (1996). Carta 71. In S. Freud, Edição standard brasileira das obras psicológicas completas de Sigmund Freud (J. Salomão, trad., Vol. 1, pp. 314-317). Rio de Janeiro: Imago. (Trabalho original publicado em 1897d)

Freud, S. (1996). Carta 69. In S. Freud, Edição standard brasileira das obras psicológicas completas de Sigmund Freud (J. Salomão, trad., Vol. 1, pp.309-311). 
Rio de Janeiro: Imago. (Trabalho original publicado em 1897e)

Freud, S. (1996). Carta 97. In S. Freud, Edição standard brasileira das obras psicológicas completas de Sigmund Freud (J. Salomão, trad., Vol. 1, pp.326-327). Rio de Janeiro, RJ: Imago. (Trabalho original publicado em 1898)

Freud, S. (1996). A interpretação dos sonhos: o despertar pelos sonhos: a função dos sonhos - sonhos de angústia. In S. Freud, Edição standard brasileira das obras psicológicas completas de Sigmund Freud (J. Salomão, trad., Vol. 5, pp. 602-614). Rio de Janeiro, RJ: Imago. (Trabalho original publicado em 1900)

Freud, S. (1996). Fragmento da análise de um caso de histeria. In S. Freud, Edição standard brasileira das obras psicológicas completas de Sigmund Freud (J. Salomão, trad., Vol. 7, pp. 15-116). Rio de Janeiro, RJ: Imago. (Trabalho original publicado em (1905 [1901])

Freud, S. (1996). Três ensaios sobre a teoria da sexualidade. In S. Freud, Edição standard brasileira das obras psicológicas completas de Sigmund Freud (J. Salomão, trad., Vol. 7, pp. 119-231). Rio de Janeiro, RJ: Imago. (Trabalho original publicado em 1905)

Freud, S. (1996). Formulações sobre os dois princípios do funcionamento mental. O caso Schereber: artigos sobre a técnica e outros trabalhos. In S. Freud, Edição standard brasileira das obras psicológicas completas de Sigmund Freud (J. Salomão, trad., Vol. 12, pp. 233-244). Rio de Janeiro, RJ: Imago. (Trabalho original publicado em 1911)

Freud, S. (1996). A disposição à neurose obsessiva- uma contribuição ao problema da escolha da neurose. O caso Schereber: artigos sobre a técnica e outros trabalhos. In S. Freud, Edição standard brasileira das obras psicológicas completas de Sigmund Freud (J. Salomão, trad., Vol. 12, pp. 337-349). Rio de Janeiro, RJ: Imago. (Trabalho original publicado em 1913)

Freud, S. (1996). Conferência XXI In S. Freud, Edição standard brasileira das obras psicológicas completas de Sigmund Freud (J. Salomão, trad., Vol. 16, pp. 325-342). Rio de Janeiro, RJ: Imago. (Trabalho original publicado em 1915-1916)
Freud, S. (1996). História de uma neurose infantil. In S. Freud, Edição standard brasileira das obras psicológicas completas de Sigmund Freud (J. Salomão, trad., Vol. 17, pp. 15-129). Rio de Janeiro, RJ: Imago. (Trabalho original publicado em 1918 [1914])

Freud, S. (1996). A psicogênese de um caso de homossexualismo numa mulher. In S. Freud, Edição standard brasileira das obras psicológicas completas de Sigmund Freud (J. Salomão, trad., Vol. 18, pp. 157-183). Rio de Janeiro, RJ: Imago. (Trabalho original publicado em 1920)

Freud, S. (1996). O ego e o id. In S. Freud, Edição standard brasileira das obras psicológicas completas de Sigmund Freud (J. Salomão, trad., Vol. 19, pp. 15-80). Rio de Janeiro, RJ: Imago. (Trabalho original publicado em 1923)

Freud, S. (1996). Inibições, sintomas e ansiedade. Um estudo autobiográfico, inibições, sintomas e ansiedade, análise leiga e outros trabalhos. In S. Freud, Edição standard brasileira das obras psicológicas completas de Sigmund Freud (J. Salomão, trad., Vol. 20, pp. 81-171). Rio de Janeiro, RJ: Imago. (Trabalho original publicado em 1926).

Gutierra, B. C. C. (2003). Adolescência, psicanálise e educação. O mestre "Possível" de adolescentes. São Paulo, SP: Avercamp.

Ladame, F. (1985). Rupture ou descontinuité. Adolescence, 3(1), 155-158.

Laplanche, J., \& Pontalis, J.-B. (2001). Vocabulário de psicanálise (4a ed.). São Paulo, SP: Martins Fontes.

Matheus, T. C. (2007). Adolescência: história e política do conceito na Psicanálise. São Paulo, SP: Casa do Psicólogo. (Coleção Clínica Psicanalítica)

Rassial, J. J. (1999). A adolescência como conceito na teoria psicanalitica. Porto Alegre, RS: Artes e Ofícios.

Saggese, E. (2001). Adolescência e psicose: transformações sociais e os desafios da clínica. Rio de Janeiro, RJ: Cia de Freud.

Stevens, A. (2004). Adolescência, sintoma da puberdade. Clínica do contemporâneo. Curinga, (20), 27-35.

Viola, D. T. D., \& Vorcaro, A. M. R. (2012). Latência, puberdade e saber. (No prelo).

Winnicott, D. W. (1974). O brincar e a realidade. Rio de Janeiro, RJ: Imago.

Recebido: 10/08/2013

Revisado: 05/02/2014

Aceito: 07/03/2014 